Int. J. Electrochem. Sci., 14 (2019) $10111-10120$

\title{
Glassy Carbon Electrode Modified with Alizarin Red S as a Working Electrode for the Analysis of Cobalt in Water and Hair Using Adsorptive Stripping Voltammetry
}

\author{
Hamed M. Al-Saidi ${ }^{1}$, Ahmed. A. Gahlan ${ }^{2, *}$ and O. A. Farghaly ${ }^{2}$ \\ ${ }^{1}$ Department of Chemistry, University College in Al - Jamoum, Umm Al-Qura University, 21955, \\ Makkah, KSA. \\ ${ }^{2}$ Chemistry Department, Faculty of Science, Al-Azhar University, Assiut branch, 71524, Assiut, \\ Egypt. \\ *E-mail: ah4424493@gmail.com
}

doi: $10.20964 / 2019.11 .50$

Received: 9 July 2019 / Accepted: 11 September 2019 / Published: 7 October 2019

In the present work, glassy carbon electrode (GCE) modified with Alizarin Red S (ARS) was employed for the determination of cobalt in waters and human hair by square wave cathodic adsorptive stripping voltammetry (SW-CASV). The method is based upon the selective and interfacial accumulation of Co (II) ion on GCE surface treated by Alizarin Red S. The parameters influencing on the determination efficiency e.g. $\mathrm{pH}$ and type of supporting electrolyte, accumulation potential and time, scan rate, and ionic strength were discussed and optimized systematically. The method submitted in the current study is able to track ultra-trace concentrations of Cobalt in variety of samples where the limit of detection (LOD) was $0.14 \pm 0.006 \mathrm{pM}$, while, the linearity was in the range of $2.00-80.00$ pM at optimezed conditions. The evaluation of the proposed method was successfully carried out by the analysis of cobalt content in natural waters and human hair and the results were compared with standard ICP method.

Keywords: Stripping voltammetry, Trace determination of cobalt, Alizarin Red S, Interfacial accumulation.

\section{FULL TEXT}

(C) 2019 The Authors. Published by ESG (www.electrochemsci.org). This article is an open access article distributed under the terms and conditions of the Creative Commons Attribution license (http://creativecommons.org/licenses/by/4.0/). 